have paradoxically prolonged OCTT excluding the role of small bowel in diarrheal symptoms

\section{IDDF2019-ABS-0145 EFFICACY AND SAFETY OF ARTIFICIAL ASCITES EFFUSION IN THE TREATMENT OF HEPATOCELLULAR CARCINOMA TUMORS WITH PERCUTANEOUS RADIOFREQUENCY ABLATION}

${ }^{1}$ Thanh Huy Nguyen*, ${ }^{2}$ Hang Viet Dao, ${ }^{2}$ Long Van Dao. ${ }^{1}$ Bach Mai Hospital, Vietnam; ${ }^{2}$ Hanoi Medical University, Vietnam

\subsection{6/gutjnl-2019-IDDFabstracts.272}

\section{Background}

1. Hepatocellular carcinoma (HCC) is a common disease in the world as well as in Vietnam. Radiofrequency ablation (RFA) is a local therapy to destroy tumor tissue by heat. In cases with difficult locations near other organs, artificial ascites is a feasible and effective technique.

2. This study was to evaluate the safety and efficacy of artificial ascites technique in the treatment of HCC tumors with percutaneous RFA.

\section{Methods}

1. An interventional longitudinal study on HCC patients having RFA indications ( $\leq 3$ tumors with each tumor size $\leq 3 \mathrm{~cm}$ or one tumor up to $5 \mathrm{~cm}$; Cirrhosis grading Child-Pugh class A or B ) and the tumor location is near diaphragm or vital organs such as kidney, gastrointestinal tract and gallbladder (with distance $<0,5 \mathrm{~cm}$ ).

2. The study was conducted in the Hepatology Department of Bach Mai hospital from October 2013 to June 2017.

Results 61 patients were performed percutaneous RFA sessions with artificial ascites.

- The mean age of patients is $57,1 \pm 10,2$; the male: female ratio is $9,2 / 1$.

- There are 54 Child-Pugh A patients (88,5\%), 7 Child-Pugh B patients $(11,5 \%)$. The mean tumor size is $3,1 \pm 0,9 \mathrm{~cm}(1-$ $4,9 \mathrm{~cm})$. There are 49 patients with 1 tumor (80,3\%), 10 patients with 2 tumors (16,4\%), 2 patients with 3 tumors $(3,3 \%)$.
- The mean volume of fluid for artificial ascites is $1691 \pm$ $535,1 \mathrm{ml}(500-2700 \mathrm{ml})$.

- The mean time to be discharged is 3,16 $\pm 0,9$ days ( $2-6$ days).

- Mild fever and abdominal pain occurred in 31,1\% cases. After the procedure, 6 patients had right pleural effusion and 1 patient had post-peritoneal fluid, all were treated well by internal medicine.

- After 1 month, 53 patients had a complete response (86,9\%), 8 patients had partial responses $(13,1 \%)$ according to mRECIST criteria and $96,7 \%$ had weight gain or stable weight.

- During follow - up time (20,6 $\pm 11,8$ months): 8 patients $(13,1 \%)$ died with the mean survival time being $17,8 \pm 12,6$ months; 19 patients $(31,1 \%)$ had a recurrence with the mean progression time being 7,5 \pm 5,7 months.

Conclusions RFA with artificial effusion is a feasible and effective technique for HCC patients having tumors with difficult locations.

\section{IDDF2019-ABS-0147 LONG-TERM OUTCOMES OF LIMITED ENDOSCOPIC SPHINCTEROTOMY PLUS LARGE-BALLOON DILATION VERSUS ENDOSCOPIC PAPILLARY LARGE-BALLOON DILATIONALONE FOR REMOVAL OF BILE DUCT STONES}

Tao Li*. Digestive Endoscopy Center, Department of Gastroenterology, Ruijin Hospital, Affiliated to Shanghai Jiao Tong University School of Medicine, China

\subsection{6/gutjnl-2019-IDDFabstracts.273}

Background Limited endoscopic sphincterotomy with large balloon dilation (ES-LBD) and endoscopic papillary large balloon dilation (EPLBD) have been proven safe and effective for removal of common bile duct (CBD) stones. However, few reports exist regarding the long-term outcomes of these techniques. The aim of this study was to assess the long-term outcomes of ES-LBD compared with EPLBD for retrieval of CBD stones.

Methods Patients with EPLBD or ES-LBD referred for CBD stones removal between June 2008 and August 2015 in our center were retrospectively reviewed. The main outcomes of complete stone clearance, ERCP-related adverse events, late

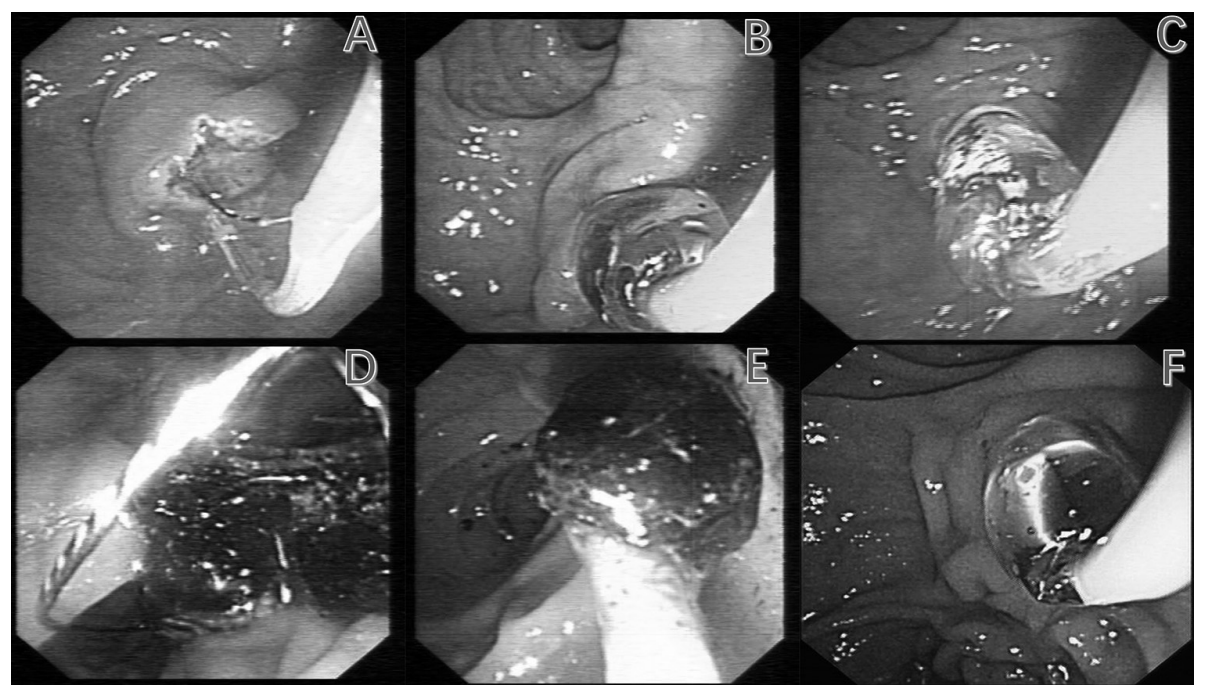

